\title{
DA TERCEIRIZAÇÃO À DESTERCEIRIZAÇÃO: APONTAMENTOS SOBRE UM DOS ASPECTOS CRUCIAIS DA FLEXIBILIZAÇÃO NAS RELAÇÕES DE TRABALHO / OUTSOURCING AND UNOUTSOURCING: NOTES ON A CRUCIAL ASPECTS OF FLEXIBILITY IN LABOR RELATIONS
}

Camila Fonseca: Bacharelanda em Direito pela Universidade Federal do Estado do Rio de Janeiro UNIRIO. Monitora da Disciplina de Direito Processual do Trabalho. Estagiária da Procuradoria Geral do Trabalho do Rio de Janeiro $-1^{\text {a }}$ Região.

Luiz Eduardo Solis: Bacharelando em Direito pela Universidade Federal do Estado do Rio de Janeiro UNIRIO. Ex-Monitor de Direito Civil I - Teoria Geral do Direito Civil. Estagiário da Procuradoria Geral do Estado do Rio de Janeiro.

Daniel Queiroz Pereira: Professor Assistente da Escola de Ciências Jurídicas da Universidade Federal do Estado do Rio de Janeiro - UNIRIO. Assistente de pesquisas da Editora Atlas S.A. Advogado. Bacharel, Mestre e Doutor em Direito da Cidade pela Universidade do Estado do Rio de Janeiro - UERJ. Pós-graduado em Direito Material e Processual do Trabalho pela Universidade Gama Filho - UGF.

Resumo: O presente artigo tem por objetivo analisar as questões prejudiciais e os benefícios acarretados pelo fenômeno da terceirização nas relações de trabalho. O estudo aborda tanto a aplicação do instituto nas atividades-meio da administração pública quanto seu crescente emprego na iniciativa privada. Buscase, também, compreender os fundamentos doutrinários e jurisprudenciais que culminaram em tendência oposta: a desterceirização, fenômeno este decorrente do mal emprego do instituto aqui abordado, sobretudo no âmbito da administração pública.

Palavras-chave: Relações de trabalho, Flexibilização, Administração Pública.

\begin{abstract}
The present article aims to analyses the benefits and the damages associated with the phenomenon of outsourcing in labor relations. This examination accosts the outsourcing uses for management of the public administration activities and its crescent use in the private sector. The article seeks to comprehend the doctrine and jurisprudence basis that culminated in the opposite trend: avoid outsourcing, phenomenon that took place because of the bad usage of the institute focused in this paperwork, especially in public administration.
\end{abstract}

Key-words: Labor relations, Flexibilization, Public Administration.

\section{Introdução}

O Direito do Trabalho é um ramo muito dinâmico da Ciência do Direito, sendo, muitas vezes, necessária uma maior flexibilização de seus pressupostos, para que o universo laboral se sustente e progrida. Contudo, essa flexibilização tem um lado prejudicial ao trabalhador, que vê cada vez mais os princípios clássicos supostamente 
protetores do lado mais fraco da relação trabalhista, serem minimizados em face das necessidades das empresas.

Segundo o renomado jurista Sérgio Pinto Martins: "flexibilização das condições de trabalho é um conjunto de regras que tem por objetivo instituir mecanismos tendentes a compatibilizar as mudanças de ordem econômica, tecnológica ou social existentes na relação entre o capital e o trabalho." ${ }^{1}$ Um exemplo seria o trabalho em tempo parcial, o teletrabalho ou trabalho a distância, o trabalho temporário, o contrato de trabalho de prazo determinado, entre outros. Portanto, a flexibilização pode serbenéfica ao trabalhador, como nos casos de redução da jornada de trabalho, como prejudicial, como nos casos da diminuição salarial.

Nessa concepção de flexibilização está incluído o conceito de terceirização, que consiste, segundo Sergio Pinto, na possibilidade de contratar terceiro para a realização de atividades que geralmente não constituem o objeto principal da empresa. Essa contratação pode compreender tanto a produção de bens como serviços, o que pode ocorrer na contratação de serviços de limpeza, de vigilância ou até de serviços temporários. Terceirização de atividade diz respeito à empresa, já de mão de obra diz respeito ao serviço.

\section{A terceirização como fenômeno da flexibilização}

A expressão "terceirização" é resultante de neologismo oriundo da palavra "terceiro", este como sinônimo de "interveniente" ou "intermediário". É neologismo construído pela ciência da administração, para enfatizar a descentralização empresarial de atividades a outrem, um terceiro à empresa.

$\mathrm{Na}$ terceirização, a relação clássica bilateral do contrato de emprego entre empregado e empregador ( $\operatorname{art} .2^{\circ}$ e $3^{\circ}$ da CLT), adquire uma estrutura triangular, em que a empresa tomadora de serviços contrata uma terceira, que utiliza empregados próprios para prestação de serviços à primeira. Para Sergio Pinto, significa a empresa contratar serviços de terceiros para suas atividades-meio. Ou seja, não estão presentes em relação ao tomador dos serviços a pessoalidade e a direção da prestação de serviços, importando o serviço em si e, ainda mais, os resultados.

Nessa estrutura triangular, em um vértice se localiza o trabalhador prestador de serviços, que realiza suas atividades junto à empresa tomadora de serviços. Em outro

\footnotetext{
${ }^{1}$ Martins, Sergio Pinto. Flexibilização das condições de trabalho. 4. Ed. São Paulo: Atlas, 2009. P.13.
} 
vértice fica a empresa terceirizante, ou prestadora, que contrata este trabalhador, firmando o contrato de trabalho correspondente à relação de emprego. E, por fím, concluindo a estrutura, há a empresa tomadora de serviços, que recebe a prestação de labor sem assumir a posição de empregadora em relação a tal trabalhador. Estabelecese, com isso, uma nova forma de gerenciamento de trabalho, transferindo os riscos sociais e trabalhistas do empreendimento principal a um terceiro (empresa prestadora de serviços), diminuindo o custo da mão de obra e objetivando o aumento da qualidade do produto.

A terceirização surge como um meio de aumentar os ganhos econômicos, flexibilizando os métodos de gestão laboral, compatíveis com os avanços tecnológicos, os quais impõem irrefutável mudança na fisionomia e organização da empresa e do trabalho. Alicerçando-se nesse avanço, as empresas mantém suas atividades-fim, seu núcleo do empreendimento, e transferem para terceiros as atividades-meio, as não essenciais para a empresa, secundárias. Assim, "elas são capazes de satisfazer as necessidades da produção e do mercado, sem que tenham de recorrer ao tradicional trabalho subordinado, que exige direção, fiscalização e custos sociais."

Entretanto, nessa estratégia de organização empresarial, muitos dos direitos trabalhistas são perdidos, como a carteira assinada e alguns benefícios decorrentes do contrato de trabalho. Não é surpresa, então, o fato dos sindicatos não simpatizarem com a terceirização. Eles afirmam que há perda de postos de trabalho, inibição do sindicalismo, perda de receitas relativas à mensalidade dos associados e da contribuição federativa, sindical e assistencial. O sindicato tenta controlar a situação firmando acordos, como, por exemplo, o da Comissão de fábrica da Volkswagen ${ }^{34}$, que garante a negociação de qualquer transferência de atividades a terceiros.

Além disso, esse fenômeno carece de estabilidade ontológica, podendo se falar em terceirização legal e ilegal para o mesmo fenômeno jurídico, sendo deixado ao Poder Judiciário a decisão acerca de cada caso concreto. A jurisprudência no Brasil cristalizou entendimento de que a terceirização só é permitida nas atividades-meio da empresa tomadora de serviços, desde que não se configurem os requisitos da relação de emprego:

\footnotetext{
${ }^{2}$ Schwartsman, Sergio; Magalhães, Daniel. Aspectos Modernos do direito Trabalhista Empresarial. Ed QuartierLatin do Brasil, São Paulo, 2010. P. 226

${ }^{3}$ http://www.estudosdotrabalho.org/anais-vii-7-seminario-trabalhoret-

4/Alessandro_de_Moura_MOVIMENTO_OPERRIO_NO_ABC_O_CASO_DA_VOLKSWAGEN_A BC.pdf. Acesso em 20 de dez. 2011
} 
pessoalidade e subordinação hierárquica direta. Contudo, o que é considerado atividademeio e atividade-fim? E como esse aspecto é visto no âmbito da Administração Pública?

O objetivo principal da terceirização não é só reduzir os custos, mas também agilizar a produção e competir no mercado, podendo investir em tecnologia e no seu desenvolvimento.

\section{Terceirização e Administração Pública}

Pode-se dizer que, no Brasil, a terceirização foi impulsionada pelo setor público, que se distanciou das críticas feitas a este fenômeno principalmente ao que concerne a transformação dos funcionários efetivos de outrora para terceirizados, aumentando, assim, a rotatividade de mão de obra e os níveis de desemprego ${ }^{5}$. Assim, a partir do advento do Decreto-Lei $n^{\circ}$. 200/67, que dispõe sobre a organização da Administração Pública Federal e estabelece diretrizes para a reforma administrativa, iniciou-se um amplo processo de descentralização das execuções destas atividades, conforme o exposto no artigo 10 do referido diploma legal.

A descentralização dos serviços públicos, ressalte-se, foi autorizada para tarefas auxiliares do Estado, de acordo com o depreendido do $\S 7^{\circ}$ do artigo 10 do Decreto-Lei $n^{\circ} 200 / 67$, que prevê a possibilidade de contratação de terceiros:

Art. 10. A execução das atividades da Administração Federal deverá ser
amplamente descentralizada.
$[\ldots .$.
$\S 7^{\circ}$ Para melhor desincumbir-se das tarefas de planejamento, coordenação,
supervisão e controle e com o objetivo de impedir o crescimento
desmesurado da máquina administrativa, a Administração procurará
desobrigar-se da realização material de tarefas executivas, recorrendo,
sempre que possível, à execução indireta, mediante contrato, desde que
exista, na área, iniciativa privada suficientemente desenvolvida e capacitada
a desempenhar os encargos de execução.

À época, a Lei ${ }^{\circ}$. 5.465/70, no seu artigo $3^{\circ}$, parágrafo único (revogado em 1997, pela Lei $\mathrm{n}^{\circ}$. 9.527), também foi no mesmo sentido, discriminando as atividades em que são possíveis a contratação no setor público por via indireta, quais sejam, as relacionadas com transporte, conservação, custódia, operação de elevadores, limpeza.

A Administração Pública, com tais medidas, teve o objetivo de otimizar seus serviços, transferindo-os para a iniciativa privada. Pode-se considerar que houve, de

\footnotetext{
${ }^{5}$ ROMITA, ArionSayão et al. (Comp.). Terceirização: Aspectos Gerais. Última decisão do STF e a Súmula 331 do TST. Novos Enfoques. Revista Magister de Direito do Trabalho e Previdenciário, Porto Alegre, n.40, p.09
} 
certo modo, uma privatização de especificas atividades do Estado, a fim de diminuir-lhe o tamanho.

Nota-se, pelas atividades executivas elencadas na Lei $\mathrm{n}^{\circ}$. 5.645/70, que são passiveis de terceirização os serviços de apoio, instrumentais, em outras palavras, a terceirização no setor público são licitas quando tratar-se de atividade-meio. Em contrapartida, não há autorização legal ao funcionamento terceirizado de serviços nas atividades-fim da Administração Pública.

Neste diapasão, leciona Dora Maria de Oliveira Ramos:

A terceirização que se cogita, em sentido estrito, é aquela em que o gestor operacional repassa a um particular por meio de contrato, a prestação de determinada atividade, como mero executor material, destituído de qualquer prerrogativa de Poder Público. Não se cuida de transferência de gestão do serviço público, mas de mera prestação de serviços. ${ }^{6}$

O Enunciado $\mathrm{n}^{\circ}$. 256, aprovado em 1986 pelo TST, o qual restringiu as possibilidades de terceirização lícita aos trabalhadores temporários e aos serviços de vigilância bancária, infelizmente não se manifestou acerca da possibilidade frente aos serviços na Administração Pública. Este Enunciado, entretanto, não ficou muito tempo em vigência.

Com a Constituição da República Federativa do Brasil (CRFB) de 1988, criou-se uma barreira ao reconhecimento de vinculo empregatício entre entes da Administração Pública devido ao disposto no artigo 37 , II e $\S 2^{\circ}$ :

\footnotetext{
Art. 37. A administração pública direta, indireta ou fundacional, de qualquer dos Poderes da União, dos Estados, do Distrito Federal e dos Municípios obedecerá aos princípios de legalidade, impessoalidade, moralidade, publicidade e, também, ao seguinte:

[...]

II - a investidura em cargo ou emprego público depende de aprovação prévia em concurso público de provas ou de provas e títulos, ressalvadas as nomeações para cargo em comissão declarado em lei de livre nomeação e exoneração ${ }^{7}$;

[...]

$\S 2^{\circ}$ - A não observância do disposto nos incisos II e III implicará a nulidade do ato e a punição da autoridade responsável, nos termos da lei.
}

\footnotetext{
${ }^{6}$ CAMPOS, José Ribeiro. A Terceirização e a Responsabilidade da Empresa Tomadora dos Serviços. São Paulo: Iob, 2006.

${ }^{7}$ A Emenda Constitucional no $\mathrm{n}^{\mathrm{o}} 19$ de 1998 alterou o texto deste inciso sem, contudo, alterar o ponto nodal da discussão trazida pelo texto. A fim de informar o texto legal atualizado, segue a norma: "II - a investidura em cargo ou emprego público depende de aprovação prévia em concurso público de provas ou de provas e títulos, de acordo com a natureza e a complexidade do cargo ou emprego, na forma prevista em lei, ressalvadas as nomeações para cargo em comissão declarado em lei de livre nomeação e exoneração".
} 
Demonstra-se a intenção do legislador constituinte em garantir a celeridade impessoal aos empregos e cargos públicos, levando aos atos realizados em contrário ao texto legal à nulidade do ato de admissão, assim como a punição da autoridade responsável nos termos legais. Nas palavras de Enio Sant’ Anna Júnior:

A exigência de concurso visa resguardar a moralidade do serviço público, coibindo o empreguismo e o apadrinhamento, fazendo prevalecer às exigências do bem comum.

[...]

Não obstante estarem [...] a moralidade pública e o trabalho humano, resguardados constitucionalmente, o trabalho humano está aclamado como direito fundamental, devendo prevalecer sobre os demais direitos. Dessa forma, devem estar a moralidade e a probidade administrativas, compatíveis com o direito fundamental de valorização e proteção do trabalho humano. ${ }^{8}$

Ressaltem-se ainda as palavras de Sérgio Pinto Martins, quando afirma que

\begin{abstract}
Administração Pública está adstrita ao principio da legalidade, devendo observar a regra constitucional. O principio da primazia da realidade não pode prevalecer diante da regra de ordem pública contida no inciso II do art. 37 da Constituição. A norma constitucional está acima das regras ordinárias da CLT e dos princípios do Direito do Trabalho, que só são aplicados em casos de lacuna da lei (art. $8^{\circ}$ da CLT). O objetivo, portanto, do concurso público é evitar escopos politiqueiros, perseguições eleitorais em razão da convivência política. ${ }^{9}$
\end{abstract}

Em contraponto ao crescente movimento de Terceirização no trabalho do setor privado, a Constituição limitava os meios de ingresso aos cargos e empregos públicos, impedindo, inclusive, o reconhecimento de vinculo empregatício com a Administração Pública mesmo em atuação ilícita, por força da norma constitucional, que queria frear a possibilidade de fraudes com os entes públicos com terceirização irregulares que resultassem no pagamento de verbas trabalhistas pelo Estado.

\title{
4. Fundamentos e limites das atividades - meio e atividades - fim
}

Para a caracterização de regularidade de uma terceirização, é importante ressaltar que as circunstâncias de cada caso concreto que irão definir se há uma terceirização lícita ou ilícita. A jurisprudência dominante afirma que só é lícita a terceirização de

\footnotetext{
${ }^{8}$ ZAINAGHI, Domingos Sávio (Org.). Contrato de Trabalho na Administração Pública sem Concurso Público: Direito ao Recebimento de Todas as Verbas Rescisórias. Revista de Direito do Trabalho, São Paulo, v. 135, n. 35, p.43-52, 01 ago. 2009.

${ }^{9}$ MARTINS, Sérgio Pinto. Referências da obra. apud CAMPOS, José Ribeiro. A Terceirização e a Responsabilidade da Empresa Tomadora dos Serviços. São Paulo: Iob, 2006,p.31.
} 
atividade-meio. Mas como diferenciar atividade-meio de atividade-fim uma vez que a produção de alta tecnologia necessita de atividades polivalentes dos trabalhadores?

Ocorre que o real significado da expressão "atividade-meio" ainda é tema de debate entre doutrinadores e magistrados no país. Leciona Sergio Pinto Martins:

\begin{abstract}
"A atividade-meio pode ser entendida como a atividade desempenhada pela empresa que não coincide com seus fins principais. A atividade não essencial da empresa, secundária, que não seu objeto central é uma atividade de apoio ou complementar. São exemplos da terceirização na atividade-meio a limpeza, a vigilância, etc. Já a atividade-fim é a atividade em que a empresa concentra seu mister, isto é, na qual é especializada à primeira vista, uma empresa que tem por atividade a limpeza não poderia terceirizar os próprios serviços de limpeza.

Certas atividades-fim da empresa podem ser terceirizadas, principalmente se compreendem a produção, como ocorre na indústria automobilística, ou na compensação de cheques, em que a compensação pode ser conferida a terceiros, por abranger operações bancarias intermediárias."
\end{abstract}

Já na visão de Paulo Henrique Teixeira:

\begin{abstract}
“A terceirização pode ser aplicada em todas as áreas da empresa definida como atividade-meio. Para identificar as áreas que podem ser terceirizadas deve-se analisar criteriosamente o contrato social das empresas e definir acertadamente a atividade-fim.

A CLT, no art. 581, $\S 2^{\circ}$ dispõe que se entende por atividade-fim a que caracterizar a unidade do produto, operação ou objetivo final, para cuja obtenção todas as demais atividades convirjam, exclusivamente em regime de conexão funcional. É ilegal a terceirização ligada diretamente ao produto final, ou seja, a atividadefim. Isolando a atividade-fim, todas as demais podem ser legalmente terceirizadas. A atividade-fim é a constante no contrato social da empresa, pela qual foi organizada. As demais funções que nada têm em comum com a atividade-fim são caracterizadas como acessórias, ou de suporte à atividade principal, as quais podem ser terceirizadas. ".
\end{abstract}

O inciso III da Sumula 331 do TST mostra que não há vínculo de emprego com o tomador quando se contratam serviços de vigilância, conservação e limpeza, assim como serviços especializados que fazem parte das atividades-meio do tomador de serviços. Contudo, não pode haver nunca a pessoalidade e subordinação direta, pois se houver, forma-se o vínculo com a empresa tomadora.

Teoricamente, a terceirização compreende uma forma de contratação que vai agregar a atividade-fim de uma empresa, normalmente a que presta os serviços, à atividade-meio de outra. Assim, a empresa tomadora de serviços permanece com sua atividade principal. Contudo, se o serviço do trabalhador é essencial à empresa, estando provadas a subordinação e a pessoalidade com o tomador dos serviços, costuma-se entender que a terceirização é ilícita.

O Recurso Ordinário $n^{\circ} .13812 / 93$, da Quarta Turma do TRT de MG, que contou com o Relator Antonio Fernando Guimarães, teve como tema a terceirização e a 
atividade-fim. Ele define bem os limites da atividade-meio e atividade-fim das empresas:

"EMENTA: TERCEIRIZAÇÃO - ATIVIDADE-FIM - Mais do que superficial, d.v., é o critério diferenciador para a legitimação da terceirização, fulcrada sempre na atividade-meio, mas jamais na atividade-fim. Ora, atividade-meio é o único caminho a se alcançar o objetivo final, inexiste, em qualquer processo produtivo, atividadefim específica, o desenvolvimento da produção é composto de elos que se entrelaçam a formar a corrente final do objetivo negocial. Como fator de especialização a somar forças na obtenção de um resultado comum não se pode negar que a terceirização se dê, também, na atividade-fim, desde que em setor autônomo do processo produtivo. Ref.:Art. $1^{\circ}$, IV, CF/88 Art. $9^{\circ}$, CLT Art. $1^{\circ}$, Dec. $1232 / 62 "$

Outro julgado ${ }^{9}$ muito interessante sobre a possibilidade de terceirização na atividade-fim é o seguinte, da Primeira Turma do TRT de MG, do Relator Cleber Lucio de Almeida, com a seguinte ementa:

"EMENTA: TERCEIRIZAÇÃO DE ATIVIDADE-FIM. O art. $2^{\circ}$ da Lei $n$. 6.019/74 (Lei do Trabalho Temporário), ao autorizar a contratação de empresas de trabalho temporário para atender à necessidade transitória de substituição do pessoal regular e permanente ou para atender a acréscimo extraordinário de serviços, admite a terceirização de atividade-fim. Note-se, porém, que o art. $2^{\circ}$ da Lei n. 6.019/74 trata de situações excepcionais - necessidade transitória de substituição de pessoal e acréscimo extraordinário de serviços - em uma clara demonstração de que a terceirização de atividade-fim não encontra respaldo em nosso ordenamento jurídico. É digno de nota, ainda, que esta mesma lei, não só limita a duração da contratação nestes moldes (art. 10), como também assegura aos trabalhadores das empresas de trabalho temporário remuneração equivalente à percebida pelos empregados da mesma categoria da empresa tomadora ou cliente (art. 12, letra "a") e torna a tomadora dos serviços temporários solidariamente responsável, no caso de falência da empresa de trabalho temporário, pelos créditos do trabalhador (art. 16), o que indica, de forma inequívoca, que a terceirização de serviços não pode ser realizada à custa da precarização das condições de trabalho dos empregados de empresa prestadora de serviços."

Outra decisão que explica a questão da responsabilidade da Administração Pública é o Recurso Ordinário ${ }^{10}$, julgado pela Quarta Turma, com o Relator Julio Bernardo do Carmo, onde se esclarece in verbis que "dentro do contexto de uma terceirização tolerada, não basta a regularidade da terceirização em si, há que se perquirir sobre o cumprimento das obrigações trabalhistas". Afirma-se, ainda, que a não persecução das aludidas obrigações pela contratada à realização de serviço terceirizado,

${ }^{9}$ TRIBUNAL REGIONAL DO TRABALHO $3^{\text {a }}$ REGIÃO. $1^{\text {a }}$ Turma. Processo: 000143515.2010.5.03.0110. RO 01435-2010-110-03-00-0. Relator Cleber Lucio de Almeida.Data de Publicação: 27/01/2012

${ }^{10}$ Processo: 0000171-13.2011.5.03.0082. RO 00171-2011-082-03-00-4. Data de Publicação: 16/01/2012. In verbis: "EMENTA: TERCEIRIZAÇÃO - ÓRGÃO PÚBLICO - RESPONSABILIDADE

SUBSIDIÁRIA. Na terceirização, a responsabilidade subsidiária do tomador dos serviços contemplada pela Súmula n. 331/TST não é excluída na hipótese de uma terceirização de serviços tolerada, mesmo em se tratando de Administração Pública ou empresas públicas a ela pertencentes. O fundamento é legal (art. 927 do Código Civil). Dentro do contexto de uma terceirização tolerada, não basta a regularidade da 


\section{Quaestio Iuris}

vol.05, $\mathrm{n}^{\circ} 01$. ISSN 1516-0351

terceirização em si, há que se perquirir sobre o cumprimento das obrigações trabalhistas pela contratada durante a vigência do contrato. E sob esse aspecto, atribui-se ao tomador dos serviços a culpa in eligendo e a culpa in vigilando, ensejadoras da responsabilidade civil que gera o dever de reparação pelo ato ilícito, que por sua vez, constitui-se na ação ou omissão, atribuível ao agente, danosa para o lesado e que fere o ordenamento jurídico, com fulcro no art. 927 do Código Civil, aplicável no âmbito do Direito do Trabalho, por força do art. $8^{\circ}$ consolidado.Com efeito, a Administração Pública tem o dever de fiscalizar o cumprimento dos contratos por ela firmados (inciso XXI e parágrafo $6^{\circ}$, artigo $37, \mathrm{CF}$ ), inclusive para verificar a integral satisfação das obrigações do trabalho assalariado, pois foi beneficiária direta dos serviços prestados. A responsabilidade subsidiária decorre tanto do disposto na lei comum (culpa contratual), quanto do entendimento do item IV Súmula 331/ TST, calcado nas regras do artigo $9^{\circ}$ e 444 da legislação consolidada. Portanto, cabe à Administração, através de seu representante, exigir a comprovação do recolhimento dos encargos sociais e previdenciários, bem como verificar a regularidade da situação dos empregados e do contrato. Esta obrigação não é prerrogativa, mas dever das partes. Nesta linha de raciocínio, somente se poderia admitir fosse afastada a responsabilidade subsidiária imposta ao órgão pertencente à Administração Pública se efetivamente provado seu eficaz controle e fiscalização quanto à observância, pela real empregadora, dos direitos trabalhistas daquele que lhe oferecia serviços, no desenrolar quotidiano do contrato levado a termo."

denota culpa in eligendo e in vigilando do tomador de serviços, ensejando

responsabilidade civil, com dever de reparação do ato ilícito.

A discussão acerca do assunto é extensa, tendo decisões controversas nos Tribunais do país. Por exemplo, o Recurso de Revista $n^{\circ} .66000-77.2008 .5 .03 .0006$ da Oitava Turma do Tribunal Superior do Trabalho reconheceu a licitude de terceirização de atividade-fim feita pela Telemar Norte Leste para atividades inerentes aos serviços de telecomunicações. O colegiado, dessa forma, negou a existência de vínculo de emprego direto com a empresa. Na interpretação da Presidente da Turma, Ministra Maria Cristina Peduzzi, a Lei Geral das Telecomunicações (Lei 9.472/97) ampliou as hipóteses de terceirização, descrevendo em seu art.60, $\S 1^{\circ}$, as atividades essenciais. Para a Ministra, a contratação de empresa interposta para a prestação de atividades inerentes, autoriza a terceirização das atividades-fim do setor. Mesmo que as tarefas desempenhadas pelo trabalhador fossem próprias de atividade-fim, a terceirização era autorizada por lei.

Esse entendimento é contrário ao do Tribunal Regional do Trabalho da $3^{\text {a }}$ Região, que julgou esse mesmo caso de forma a ser ilícita a terceirização, por constatar que as tarefas executadas pelo trabalhador enquadravam-se entre as atividades finalísticas da operadora, e, portanto, não poderiam ficar a cargo de empresa interposta. $^{10}$

No fenômeno da terceirização, a empresa prestadora de serviços possui trabalhadores permanentes, mas trabalhando para tomadores diversos, que utilizam a

\footnotetext{
${ }^{10}$ Disponível em: http://www.conjur.com.br/2010-mar-16/tst-admite-terceirizacao-atividade-fimsetortelecomunicacoes. Acesso em 20 de dez. de 2011.
} 
mão de obra desta quando necessária. Se houvesse a hipótese de que toda a empresa tomadora restasse composta somente por trabalhadores autônomos terceirizados, estaria configurada a ilicitude, pois haveria a necessidade permanente de todos esses trabalhadores para o funcionamento da atividade-fim da empresa e, com isso, a subordinação e pessoalidade. Por exemplo, se uma empresa de mudanças terceirizasse todos os seus serviços de mudança, estaria terceirizando uma necessidade permanente, configurando a habitualidade na prestação de serviços, e o recebimento de ordens do terceirizador, configurando a subordinação e, com isso, o vínculo empregatício. Deve-se também evitar a terceirização de pessoas físicas, já que o contrato de trabalho forma-se apenas com estas, e não com pessoas jurídicas (art. $3^{\circ}$ da CLT).

Configurada a hipótese de terceirização ilícita, como garante a melhor doutrina,desfaz-se judicialmente o vínculo com o empregador aparente, reconhecendose, para todos os efeitos, a relação de emprego do obreiro com o empregador dissimulado, efetivo tomador dos serviços. Como visto, semelhante resultado jurídico só não pode ocorrer quando o tomador dos serviços for entidade da Administração Pública Direta, Indireta ou Fundacional (art.37, II e $\S 2^{\circ}, \mathrm{CRFB} / 88$ ).

Um exemplo mais evidente de terceirização é o realizado na indústria automobilística, em que praticamente esta apenas monta o automóvel, sendo todas as peças fabricadas por terceiros, seguindo a padronização imposta pela montadora de veículos. Trata-se, portanto, de terceirização na atividade-fim da empresa, que é produzir o automóvel. Esse tipo de atividade existe há muito tempo e não há qualquer veto quanto a ela.

Um outro aspecto é que, de acordo com a doutrina de Schwartsman e Magalhães ${ }^{11}$, não há ilicitude na contratação de empresa interposta para a realização dos serviços prestados a empresas comissionarias ou permissionárias de serviço público, já que a Lei 8.987/95 em seu artigo 25, combinada com o art.175 da CRFB, expressamente autoriza a terceirização inerente a acessórios e complementares aos serviços prestados por concessionárias de serviços de energia elétrica:

"Art. 25. Incumbe à concessionária a execução do serviço concedido, cabendo-lhe responder por todos os prejuízos causados ao poder concedente, aos usuários ou a terceiros, sem que a fiscalização exercida pelo órgão competente exclua ou atenue essa responsabilidade.

\footnotetext{
${ }^{11}$ SCHWARTSMAN, Sergio; Magalhães, Daniel. Aspectos Modernos do direito Trabalhista Empresarial. Ed QuartierLatin do Brasil, São Paulo, 2010. p. 226
} 
$\S 1^{\circ}$. Sem prejuízo da responsabilidade a que se refere este artigo, a concessionária poderá contratar com terceiros o desenvolvimento de atividades inerentes, acessórias ou complementares ao serviço concedido, bem como a implementação de projetos associados.

Como alude o parágrafo primeiro da referida lei, o vocábulo "inerente" se refere à atividade diretamente relacionada com a própria execução do serviço, a atividade-fim. Portanto, não se restringe à atividade-meio, nesse caso específico legislado. Assim, todas as atividades de uma concessionária podem ser objeto de execução por terceiro, e ela responderá sempre, total e integralmente, por todas as exigências legais, regulamentares e contratuais, perante o poder concedente (art.31, I a VIII, L.8.987/95, c/c art.38, da mesma lei).

\section{Evolução do entendimento do TST, Constituição Federal e a contratação irregular na Administração Pública}

Em 1993, houve a Revisão do Enunciado $n^{\circ}$. 256, após requerimento do Ministério Público do Trabalho, uma vez que o aludido dispositivo legal gerou uma série de divergências interpretativas acerca das possibilidades e método em que seria lícita a terceirização dos serviços realizados por entes da Administração Pública. Desta maneira, o TST editou a Súmula de Jurisprudência $n^{\circ}$. 331, revisando, ampliando e alterando o Enunciado que o precedeu. A Súmula assim dispõe:

I - A contratação de trabalhadores por empresa interposta é ilegal, formando-se o vínculo diretamente com o tomador dos serviços, salvo no caso de trabalho temporário (Lei $\mathrm{n}^{\circ}$ 6.019, de 03.01.1974).

II - A contratação irregular de trabalhador, mediante empresa interposta, não gera vínculo de emprego com os órgãos da administração pública direta, indireta ou fundacional (art. 37, II, da CF/1988).

III - Não forma vínculo de emprego com o tomador a contratação de serviços de vigilância (Lei $n^{\circ} 7.102$, de 20-06-1983), de conservação e limpeza, bem como a de serviços especializados ligados à atividade-meio do tomador, desde que inexistente a pessoalidade e a subordinação direta.

IV - O inadimplemento das obrigações trabalhistas, por parte do empregador, implica a responsabilidade subsidiária do tomador dos serviços, quanto àquelas obrigações, desde que hajam participado da relação processual e constem também do título executivo judicial (art. 71 da Lei no .8 .666 , de 21.06.1993).

Há uma importância indubitável deste diploma legal, uma vez que delimita juridicamente a terceirização, tornando-a "duplamente importante, seja para o bem como para o mal. Para o bem porque - em razão dos próprios limites - ajuda a conter o fenômeno. Para o mal, porque - dentro dos mesmos limites - ela o legitima e reforça ${ }^{13 "}$.

A Súmula no .331 reafirma que, na Administração Pública, "a terceirização pode ser entendida como transferência para a entidade pública ou privada, por meio de 
contrato de prestação de serviços ou de fornecimento de bens, da execução de atividade que não constitua o núcleo substancial do Estado, conservando a terceirizante a gestão estratégica e operacional de atividade contratada." ${ }^{\prime 4}$. Estão, enfim, afastadas as necessidades de realização de concurso público para as denominadas atividades-meio. Além disso, explicita um ponto que gerou na Justiça e ainda se irradia na doutrina uma enorme discussão: a ilicitude da terceirização ilícita no serviço público não enseja

${ }^{13}$ ROMITA, ArionSayão et al. (Comp.). Terceirização: Aspectos Gerais. Última decisão do STF e a Súmula 331 do TST. Novos Enfoques. Revista Magister de Direito do Trabalho e Previdenciário, Porto Alegre, n. , p.11, 01 mar. 2011. 14

CAMPOS, José Ribeiro. A Terceirização e a Responsabilidade da Empresa Tomadora dos Serviços. São Paulo: Iob, 2006.

vinculo empregatício entre empregado e ente administrativo, visto a previsão constitucional de prévio concurso público.

Neste entendimento segue a Lei $\mathrm{n}^{\circ}$. 8.666/93, que regulamenta o art. 37, inciso XXI, da Constituição Federal e institui normas para licitações e contratos da Administração Pública. Destaque-se o artigo $6^{\circ}$, incisos I e II, que define contratos e licitações cujos objetos são obra e serviço:

Art. $6^{-}$Para os fins desta Lei, considera-se:

I - Obra - toda construção, reforma, fabricação, recuperação ou ampliação, realizada por execução direta ou indireta;

II - Serviço - toda atividade destinada a obter determinada utilidade de interesse para a Administração, tais como: demolição, conserto, instalação, montagem, operação, conservação, reparação, adaptação, manutenção, transporte, locação de bens, publicidade, seguro ou trabalhos técnico-profissionais

De mesma forma, o artigo 13 da aludida Lei, define as atividades consideradas como técnico-profissionais especializados:

Art. 13. Para os fins desta Lei, consideram-se serviços técnicos profissionais especializados os trabalhos relativos a:

I - estudos técnicos, planejamentos e projetos básicos ou executivos;

II - pareceres, perícias e avaliações em geral;

III - assessorias ou consultorias técnicas e auditorias financeiras;

III - assessorias ou consultorias técnicas e auditorias financeiras ou tributárias;

(Redação dada pela Lei no 8.883 , de 1994)

IV - fiscalização, supervisão ou gerenciamento de obras ou serviços; V

- patrocínio ou defesa de causas judiciais ou administrativas;

VI - treinamento e aperfeiçoamento de pessoal;

VII - restauração de obras de arte e bens de valor histórico. 
Saliente-se que, assim como acontece com a terceirização no setor privado, também na Administração Pública é imperioso verificar se a atividade terceirizada está ligada à atividade-fim ou à atividade-meio.

Diante de tais fatos, demonstra-se a confusão existente, surgindo questionamentos acerca da possibilidade de a terceirização poder atingir quaisquer atividades especiais que devem ser executadas pelo Estado. Na justiça e segurança, por exemplo, já que são admitidas suas execuções por particular. Ensina Dora Maria de Oliveira Ramos que quando se tratar de ente público buscando atingir um objetivo específico, poderá terceirizar uma atividade considerada como atividade-fim. A autora cita o exemplo de fundação pública cuja função é distribuir remédios a determinada área, poderá contratar laboratório privados para complementar a atividade, produzindo os medicamentos ${ }^{12}$.

Normativamente, em 1994, surgiu a Lei $\mathrm{n}^{\circ} .8 .863$, que estendeu as possibilidades de terceirização no setor público, para os serviços de vigilância e transporte de valores os quais antes se restringiam ao segmento bancário (art. 10, §2 Lei $^{\circ}$. 7.102/83, modificada pela Lei $\mathrm{n}^{\circ}$. 8.863/94).

No final da década de 1990, foi editado o Decreto $\mathrm{n}^{\circ}$. 2.271/97, que tendo em vista o disposto no $\S 7^{\circ}$ do art. 10 do Decreto-Lei $n^{\circ}$. 200, dispôssobre a contratação de serviços pela Administração Pública Federal direta, autárquica e fundacional, em substituição à revogada Lei nº. 5.465/70.

Este Decreto, no seu artigo $1^{\circ}$, caput e parágrafo primeiro, permite a execução indireta das atividades materiais acessórias, instrumentais ou complementares no âmbito da Administração Pública central. Em contraponto, o parágrafo segundo exclui a possibilidade de terceirização para "as atividades inerentes às categorias funcionais abrangidas pelo plano de cargos do órgão ou entidade, salvo expressa disposição legal em contrário ou quando se tratar de cargo extinto, total ou parcialmente, no âmbito do quadro geral de pessoal".

Em estrita consonância com o artigo 37 da CRFB, o aludido Decreto, em seu $\operatorname{artigo} 4^{\circ}$, diferencia os serviços de intermediação de mão de obra:

Art. $4^{\circ}$. É vedada a inclusão de disposições nos instrumentos contratuais permitam:

(...)

\footnotetext{
${ }^{12}$ CAMPOS, José Ribeiro. A Terceirização e a Responsabilidade da Empresa Tomadora dos Serviços. São Paulo: Iob, 2006.
} 
II - Caracterização exclusiva do objeto como fornecimento de mão de obra.

(...)

IV - Subordinação dos empregados da contratada à administração da contratante.

Como corolário lógico, o legislador pátrio tentou ao máximo bloquear o vinculo empregatício entre empregado terceirizado e ente da Administração Pública com propósito de que a terceirização não servisse de uma entrada "pela janela" no serviçopúblico.

Contudo, urge observar que por vezes o ato ilícito não é praticado pelo trabalhador seja por acreditar no seu empregador indiscriminadamente, negligência ou mesmo desconhecimento, ele presta os serviços à população de modo ilícito, podendo jamais receber todas as verbas rescisórias em caso de dispensa.

De certo que, por força do inciso II do artigo 37 da CRFB, o funcionário não pode ter seu vinculo firmado com a empresa tomadora de serviços. Busca-se manter garantida que a única forma de entrada ao serviço público deve ser realizada via concurso público. Este dispositivo legal é reforçado, como visto, pela orientação expressa no inciso II, da Súmula nº. 331. Portanto, conforme explica José Ribeiro Campos "mesmo se ocorrer contratação irregular de trabalhador, por meio de empresa de prestação de serviços, não caracterizará a relação de emprego com a Administração Pública". ${ }^{13}$

Não obstante, tal entendimento, de acordo com a Orientação Jurisprudencial $\mathrm{n}^{\circ}$. 321 da Seção de Dissídios Individuais, permite o estabelecimento de vinculo empregatício com a Administração Pública aos casos anteriores à promulgação da Constituição Federal de 1988. Assim estabelece a referida O.J.:

"321. Vínculo empregatício com a administração pública. Período anterior à CF/1988. Salvo os casos de trabalho temporário e de serviços de vigilância, previstos nas Leis $\mathrm{n}^{\mathrm{o}} .6 .019$, de 3 de janeiro de 1974, e 7.102, de 20 de junho de 1983, é ilegal a contratação de trabalhadores por empresa interposta, formando-se o vinculo empregatício diretamente com o tomador dos serviços, inclusive ente público, em relação ao período anterior à vigência da $\mathrm{CF} / 88$ ".

Mediante tais considerações, não resta dúvidas que os preceitos legais atestam como terceirização lícita as hipóteses elencadas na Súmula nº. 331, apenas. Enquanto as ilícitas são aquelas em que a contratação realiza-se de forma irregular sem observar os parâmetros dispostos nesta súmula.

\footnotetext{
${ }^{13}$ CAMPOS, José Ribeiro de. A Terceirização e a Responsabilidade da Empresa Tomadora dos Serviços. São Paulo: Iob, 2006,p.45.
} 
Ressalte-se, contudo, que as hipóteses de pessoalidade e subordinação são válidas para o reconhecimento de vínculo empregatício com a Administração Pública, não sendo escusado ao administrador, entretanto, da responsabilidade administrativa. Ainda assim, há autores que creem que não cabe, à empresa tomadora de serviços apenas a contraprestação salarial, mas todos os efeitos decorrentes do contrato de trabalho que não atingem o empregado, uma vez que a norma constitucional prevê a nulidade do ato de contratação, mas ao trabalhador que empregou sua força de trabalho, jamais se conseguirá o retorno ao status quo ante da celebração do contrato.

A necessidade da Administração Pública não agredir os direitos fundamentais, faz com que a Súmula 331 do TST, portanto, declare que os entes administrativos do Estado, ainda que tenham a permissão legal para terceirizar seus serviços, poderão responder subsidiariamente pelas verbas trabalhistas, como medida a que estes entes, para evitarem tal medida, atuem na fiscalização da empresa por eles contratada, conforme o inciso IV da Súmula, alterado em 11 de setembro de 2000, pela Resolução $n^{\circ} .96$ do TST:

IV - O inadimplemento das obrigações trabalhistas, por parte do empregador, implica na responsabilidade subsidiária do tomador dos serviços, quanto àquelas obrigações, inclusive quanto aos órgãos da administração direta, das autarquias, das fundações públicas, das empresas públicas e das sociedades de economia mista, desde que hajam participado da relação processual e constem também do titulo executivo judicial. (art. 71 da Lei no 8.666/93. (Alterado pela Resolução nº 96, de 11.09.00. DJ 19.09.00)

Embora haja previsão de responsabilidade subsidiária dos entes públicos, alguns autores afirmam que isto fere a Constituição, enquanto outros acreditam que esta é a redação mais razoável, a fim de proteger os direitos fundamentais dos trabalhadores. Ao todo, são três correntes interpretativas que se apresentam, conforme expõe Mauricio Godinho Delgado:

"A primeira delas considera que a terceirização ilícita, além de não gerar vinculo empregatício entre o prestador de serviços e a Administração Pública, também não produz qualquer crédito trabalhista em favor do trabalhador terceirizado.

A segunda vertente sustenta a validade do vinculo empregatício entre trabalhador terceirizado e o ente estatal tomador de serviços, '(...) que assume, em consequência, a posição de empregador desde o inicio da relação econômica verificada'.

Já a terceira corrente assegura ao trabalhador terceirizado "todas as garantias legais e normativas aplicáveis ao empregado estatal direto que cumpre a mesma função no ente estatal tomador de serviços. Ou todas as verbas trabalhistas legais e normativas próprias á função especifica exercida pelo trabalhador terceirizado junto ao ente estatal beneficiado pelo trabalho. Verbas trabalhistas apenas - sem retificação, 
contudo, de CTPS quanto à entidade empregadora formal, já que este tópico é objeto de expressa vedação constitucional'.",14

Para a jurisprudência pátria "a contratação irregular de trabalhador, mediante empresa interposta, não gera vínculo de emprego com ente da Administração Pública, não afastando, contudo, pelo princípio da isonomia, o direito dos empregados terceirizados às mesmas verbas trabalhistas legais e normativas asseguradas àqueles contratados pelo tomador dos serviços, desde que presente a igualdade de funções" (OJ $n^{\circ} .383$ da SDI-1, do TST).

\section{Novo entendimento jurisprudencial: $\mathrm{ADC} \mathrm{n}^{\circ} .16$ de 2010}

Tal conjuntura, entretanto, voltou a modificar-se depois do julgamento da ADC $\mathrm{n}^{\mathrm{o}}$. 16, de 2010, quando o STF pronunciou a constitucionalidade do artigo 71, da Lei 8.666/93, que prevê:

Art. 71. O contratado é responsável pelos encargos trabalhistas, previdenciários, fiscais e comerciais resultantes da execução do contrato.

$\S 1^{\underline{0}}$ A inadimplência do contratado, com referência aos encargos trabalhistas, fiscais e comerciais não transfere à Administração Pública a responsabilidade por seu pagamento, nem poderá onerar o objeto do contrato ou restringir a regularização e o uso das obras e edificações, inclusive perante o Registro de Imóveis. (Redação dada pela Lei $n^{\circ} .9 .032$, de 1995)

$\S 2^{\mathrm{o}} \quad$ A Administração Pública responde solidariamente com o contratado pelos encargos previdenciários resultantes da execução do contrato, nos termos do art. 31 da Lei $n^{\circ}$. 8.212, de 24 de julho de 1991. (Redação dada pela Lei $\mathrm{n}^{\circ}$. 9.032, de 1995)(grifos nossos).

Neste contexto, fica claro que este entendimento do STF vedou à Justiça do Trabalho a aplicação da responsabilidade subsidiária à Administração Pública, como se interpretava pela literalidade da Súmula nº 331.

Esta decisão, entretanto, trouxe um grande temor. $O$ afastamento da responsabilidade subsidiária da Administração Pública pela falta de fiscalização dos direitos dos trabalhadores terceirizados. Esta preocupação afetou inclusive os Ministros do Supremo, como se depreende da fala do Ministro Gilmar Mendes:

Bem verdade que os conflitos que tem sido suscitados pelo TST fazem todo o sentido e talvez exijam dos órgãos de controle, seja TCU, seja Tribunal de Contas do Estado, os responsáveis pelas contas dos municípios, que haja realmente fiscalização, porque realmente o pior dos mundos pode ocorrer para o empregado que presta o serviço. A empresa recebeu, certamente

\footnotetext{
${ }^{14}$ Citação encontrada na obra ROMITA, ArionSayãoet al. (Comp.). Terceirização: Aspectos Gerais. Última decisão do STF e a Súmula 331 do TST. Novos Enfoques. Revista Magister de Direito do Trabalho e Previdenciário, Porto Alegre, n. 40, p.09-35, jan-fev. 2011.
} 
recebeu da administração, mas não cumpriu os deveres elementares, então essa decisão continua posta. Foi o que o TST de alguma forma tentou explicitar ao não declarar a inconstitucionalidade da lei e resguardar a idéia da súmula, mas que haja essa culpa in vigilando é fundamental (...). Nós tivemos até esse caso aqui mesmo na administração do tribunal, né? (...). Talvez aqui reclame-se normas de organização e procedimentos por parte dos próprios órgãos que tem que fiscalizar, que inicialmente são órgãos contratantes, e depois órgãos fiscalizadores, de modo que haja talvez até uma exigência de demonstração de que se fez o pagamento, o cumprimento, pelo menos das verbas elementares, o pagamento de salário, o recolhimento da previdência social e do FGTS.

Data vênia, a maioria dos Ministros entendia que era possível compatibilizar a constitucionalidade do artigo 71, da Lei $n^{\circ} .8 .666 / 93$ e o dever do Estado de zelar pelos direitos dos trabalhadores que lhe prestam serviços terceirizados. Ilustram esse entendimento, em artigo recente ${ }^{15}$, Márcio Túlio Viana, Gabriela Neves Delgado e Helder Santos Amorim, ao lecionar que o Estado tem, "de forma correlata e proporcional, o dever de fiscalizar eficientemente a execução dos seus contratos de terceirização, por imperativo de legalidade e moralidade pública (Constituição, art. 37 , caput), inclusive em relação ao adimplemento dos direitos dos trabalhadores terceirizados, tendo em vista que se trata de direitos fundamentais". Desta maneira, ao se fiscalizar o contrato de prestação de serviços, fica incumbido ao Estado, intrinsecamente, o cumprimento dos direitos dos trabalhadores terceirizados. Essa extensão do limite constitucional de fiscalização dos direitos dos empregados terceirizados implica, em caso de inobservância, na responsabilidade da Administração Pública do não adimplemento dos direitos que por ela deveriam ser fiscalizados e preservados.

Não se trata, aqui, de mera formalização de vínculo de emprego, uma vez que o padrão fiscalizatório da lei exige o envolvimento direto e diário entre empregados da sociedade empresária contratada e Administração, mas da necessidade de comprovação por parte desta de que promoveu todos os procedimentos legais e extra legais indispensáveis para o controle do contrato de execução de serviço público, englobando o adimplementos dos empregados.

\footnotetext{
${ }^{15}$ ROMITA, ArionSayão et al. (Comp.). Terceirização: Aspectos Gerais. Última decisão do STF e a Súmula 331 do TST. Novos Enfoques. Revista Magister de Direito do Trabalho e Previdenciário, Porto Alegre, n.40, p.09-35, jan-fev. 2011.
} 
Desta forma, o TST, a fim de unificar o entendimento na Justiça do Trabalho, editou a Resolução $n^{\circ}$. 174/2011, alterando a Súmula $n^{\circ}$. 331, modificando o inciso IV e incluindo os incisos V e VI:

IV - O inadimplemento das obrigações trabalhistas, por parte do empregador, implica a responsabilidade subsidiária do tomador dos serviços quanto àquelas obrigações, desde que haja participado da relação processual e conste também do título executivo judicial.

V - Os entes integrantes da Administração Pública direta e indireta respondem subsidiariamente, nas mesmas condições do item IV, caso evidenciada a sua conduta culposa no cumprimento das obrigações da Lei n. ${ }^{\circ}$ 8.666, de 21.06.1993, especialmente na fiscalização do cumprimento das obrigaçõescontratuais e legais da prestadora de serviço como empregadora. A aludida responsabilidade não decorre de mero inadimplemento das obrigações trabalhistas assumidas pela empresa regularmente contratada.

VI - A responsabilidade subsidiária do tomador de serviços abrange todas as verbas decorrentes da condenação referentes ao período da prestação laboral.

\section{Fenômeno da "Desterceirização"}

No início dos anos 2000, o Ministério Público do Trabalho iniciou uma série de ações contra os órgãos da administração direta, as autarquias, as fundações públicas, as empresas públicas e as sociedades de economia mista, a fim de encerrar com o crescente número de terceirizações irregulares e quadros funcionais que contavam com número de empregados terceirizados superior aos dos concursados, demonstrando-se uma enorme burla às normas de terceirização. Esta série de ações denominou-se como um movimento de "desterceirização" do setor público.

O Parquet Trabalhista, atendendo a denúncias de empregados e ex-funcionários e investigando com o Tribunal de Contas da União os entes administrativos do Estado, ajuizou uma série de ações a fim de corrigir as irregularidades existentes frente às normas de terceirização na Administração Pública.

Entre as constatações, descobriu-se que havia a contratação de trabalhadores em serviços terceirizados que deveriam ser executados por funcionários concursados, além disso, que estes terceirizados recebiam salários inferiores àqueles que exerciam a mesma função, mas aprovados em concurso público. Não obstante, o treinamento dos empregados oriundos da terceirização era menor, assim como estes eram mais propensos a acidentes de trabalho. ${ }^{16}$

Entre as ações ajuizadas, algumas merecem destaque especial, como as ocorridas

\footnotetext{
${ }^{16}$ FERRAZ, Fernando Basto. Terceirização e demais formas de flexibilização do trabalho. São Paulo: Ltr, 2006.
} 
em face da Caixa Econômica Federal (CEF), Banco do Brasil, FURNAS e PETROBRAS $^{17}$.

A Ação Civil Pública do Ministério Público Trabalho ajuizada em desfavor da CEF em 2001, questionou as contratações de funcionários terceirizados no lugar dos concursados. Com isto, a Caixa Econômica comprometeu-se a substituir gradualmente parte dos 25 mil empregados terceirizados até 2007 por concursados, em acordo firmado em 2004. ${ }^{18}$

Outra instituição financeira acionada pelo Ministério Público foi o Banco do Brasil. O banco federal habitualmente contrata seus funcionários por meio de cooperativas de trabalho, levando a estimativa de que cerca de $40 \%$ dos empregados da instituição no país são cooperados ou estagiários, segundo o Sindicato dos Bancários de São Paulo e da $\mathrm{CNB}^{19}$. A ação ajuizada pelos promotores trabalhistas visa o encerramento deste tipo de prática.

Assim como com o Banco do Brasil, a Ação Civil Pública ajuizada contra Eletrobras FURNAS, pelo MP do Trabalho do Rio de Janeiro, tinha por fundamento a substituição dos trabalhadores cooperados (o quadro conta com cerca de 2.500) por concursados.

Nesta esteira, a Federação Única dos Petroleiros (FUP) exigiu o fim da terceirização da PETROBRAS em setores como manutenção ${ }^{20}$ devido ao perigo do trabalho que exige treinamento especializado. Assim, nessas atividades requereu-se abertura de concurso público.

Devido a estas e outras ações que se desencadeavam pelo país, em dezembro de 2007, firmou-se um termo de conciliação entre Ministério Público do Trabalho e Advocacia Geral da União e Ministério do Planejamento, na $17^{\circ}$ Vara da Justiça do Trabalho, no qual o Governo Federal comprometeu-se em regularizar a situação de seus aproximadamente 33 mil empregados terceirizados, substituindo-os por funcionários contratados até $2010 .^{21}$

\footnotetext{
${ }^{17}$ Idem

${ }^{18}$ FERRAZ, Fernando Basto. Terceirização e demais formas de flexibilização do trabalho. São Paulo: Ltr, 2006.

${ }^{19}$ Idem.

${ }^{20}$ Idem.

${ }^{21}$ ZAINAGHI, Domingos Sávio (Org.). A Administração Pública e a responsabilidade trabalhista na terceirização: matéria submetida ao Supremo Tribunal Federal. Revista de Direito do Trabalho, São Paulo, n.133 , p.186-197, jan-mar. 2009.
} 
Insta observar que a Caixa Econômica Federal, somente em 2009, após portaria do Departamento de Coordenação e Controle das Empresas Estatais (no Diário Oficial da União do dia 07 de janeiro), pode chamar os aprovados no concurso realizado em 2008, atendendo, assim, o acordo realizado com o Ministério Público do Trabalho. ${ }^{22}$ Em contrapartida, o Banco do Brasil teve aumento de seus números de funcionários terceirizados em $2010^{26}$.

Quanto a estatal Eletrobras FURNAS, conforme apurado em junho de 2011, pela Folha Dirigida, a empresa conseguiu uma liminar que suspendeu a decisão de 2010 do TCU (Tribunal de Contas da União) que previa a substituição dos trabalhadores terceirizados por concursados. O STF, que concedeu a liminar, acreditou que o afastamento dos funcionários terceirizados colocaria em risco o fornecimento de energia elétrica no país.

Não bastasse isto, a PETROBRAS, que foi pressionada pelo TCU e MPT a diminuir o contingente de funcionários terceirizados, quase dobrou este número entre 2005 e 2010. A questão mais delicada presente está no modo o qual a estatal divulga seu número de funcionários. Oficialmente, os empregados terceirizados estão sendo substituídos, mas "Mariângela Mundim, gerente de Planejamento de Recursos Humanos da Petrobras, diz que conceitos de mão de obra terceirizada estão sendo revistos pela estatal e que funcionários de empresas que prestam serviço fora das unidades da companhia estão sendo excluídos das estatísticas. Ela confirma que não houve demissão e que os terceirizados que trabalhavam fora das instalações da empresa eram incluídos 'até por uma questão de contabilização de acidentes'"23.

Cumpre salientar, porém, que, segundo a Folha Dirigida, esta política de desterceirização tentada principalmente pelo Ministério Público do Trabalho, deverá continuar apesar da suspensão parcial dos concursos públicos anunciado pelo Governo Federal, de forma que seja cumprido o intento do Termo de Conciliação homologado em 2007 pela União.

\footnotetext{
${ }^{22}$ http://g1.globo.com/Noticias/Concursos_Empregos/0,,MUL946381-9654,00.html. Acesso em: 20 de jan. 201126

PETROBRAS MUDA CRITÉRIO E 20 MIL TERCEIRIZADOS DESAPARECEM DE SUAS ESTATÍSTICAS. O Globo, 25 maio 2011.

${ }^{23}$ http://oglobo.globo.com/economia/mat/2011/05/21/petrobras-muda-criterio-20-milterceirizadosdesaparecem-de-suas-estatisticas-924510016.asp\#ixzz1Ocm2QgbS. Acesso em: 20 de jan. 2011
} 
Isto consta no Ofício $\mathrm{n}^{\mathrm{o}}$. 703 da Secretaria-Executiva do Ministério do Planejamento e confirma-se pela Assessoria de Comunicação Social do Planejamento, que informou o novo prazo para que as substituições fossem integralmenterealizadas: 31 de dezembro de 2012. Sob tais perspectivas, os entes da Administração Pública, poderão chamar os classificados nos concursos realizados nos anos anteriores, para que possam preencher as vagas deixadas pelos terceirizados gradativamente substituídos.

\section{Conclusão}

Resta cristalino que, a terceirização é um fenômeno com características prejudiciais e benéficas à logística laboral moderna no foco do empregador, com intuito de diminuição de custos, principalmente nas atividades-meio. Entretanto, aos trabalhadores, a prática, caso mal fiscalizada, pode mitigar direitos conquistados devido às fraudes nos processos de terceirização.

A gravidade no fenômeno perpassa no papel da Administração Pública, propulsora da terceirização no país, apesar das críticas iniciais que este fenômeno acarretaria na inadvertida transformação dos funcionários efetivos de outrora para terceirizados, aumentando, assim, a rotatividade de mão de obra e os níveis de desemprego. A fragilidade da capacidade de controle da atuação do próprio Estado frente ao desenfreado método de terceirização utilizado pela Administração Pública e os questionamentos legais dos dispositivos constitucionais resultaram num inchaço do número de trabalhadores terceirizados nas autarquias, empresas, fundações e demais órgãos públicos, que exerciam, inclusive, as respectivas atividades-fins para quais as citadas pessoas jurídicas de direito público foram constituídas.

Atualmente, encontra-se em relevância o processo de desterceirização, precipuamente pela Justiça do Trabalho, através de uma série de Termos de Compromissos de Ajustamento de Conduta (TAC), celebrados em sua seara. Esta movimentação, cujo objetivo é a diminuição da terceirização, principalmente a ilícita, nos órgãos, empresas, fundações e demais entes da Administração Pública, como se percebe, é um dos focos de combate conjunto do Ministério Público do Trabalho, sindicados e confederações, e ações dos tipos acima citadas se expandem pelo Brasil. Há de se observar, contudo, que ainda há uma grande resistência a este movimento de desterceirização, por causa da política dos últimos governos, salientando-se o da 
presidente Dilma Rousseff, cujo objetivo é de redução de gastos e diminuição de concursos públicos.

\section{REFERÊNCIAS:}

CAMPOS, José Ribeiro.A Terceirização e a Responsabilidade da Empresa Tomadora dos Serviços. São Paulo: Iob, 2006.

CARELLI, Rodrigo de Lacerda. Terceirização e Intermediação de Mão-de-Obra. Rio de Janeiro: Renovar, 2000.

FERRAZ, Fernando Basto. Terceirização e demais formas de flexibilização do trabalho.São Paulo: Ltr, 2006.

MARTINS, Sergio Pinto. Flexibilização das condições de trabalho. 4. Ed. São Paulo: Atlas, 2009.

MARTINS, Sergio Pinto. Terceirização e o Direito do Trabalho. 29. ed. São Paulo: Atlas, 2011.

SCHWARTSMAN, Sergio; Magalhães, Daniel. Aspectos Modernos do direito Trabalhista Empresarial. Ed QuartierLatin do Brasil, São Paulo, 2010.

SCHWARTSMAN, Sergio; Magalhães, Daniel. Aspectos Modernos do direito Trabalhista Empresarial. Ed QuartierLatin do Brasil, São Paulo, 2010.

PETROBRAS MUDA CRITÉRIO E 20 MIL TERCEIRIZADOS DESAPARECEM DE SUAS ESTATÍSTICAS. O Globo, 25 maio 2011. http://g1.globo.com/Noticias/Concursos_Empregos/0,,MUL946381-9654,00.html. Acesso em: 20 de jan. 2011.

http://oglobo.globo.com/economia/mat/2011/05/21/petrobras-muda-criterio-20milterceirizados-desaparecem-de-suas-estatisticas-924510016.asp\#ixzz1Ocm2QgbS. 
Acesso em: 20 de jan. 2011.

http://www.conjur.com.br/2010-mar-16/tst-admite-terceirizacao-atividade-fimsetortelecomunicacoes. Acesso em 20 de dez. de 2011.

http://www.estudosdotrabalho.org/anais-vii-7-seminario-trabalho-ret2010/Alessandro_de_Moura_MOVIMENTO_OPERRIO_NO_ABC_O_CASO_DA_V OLKSWAGEN_ABC.pdf. Acesso em 20 de dez. 2011.

Revista de Direito do Trabalho, São Paulo, n.133, jan-mar. 2009.

Revista de Direito do Trabalho, São Paulo, v. 135, n. 35, jul.-set.. 2009.

Revista Magister de Direito do Trabalho e Previdenciário, Porto Alegre, n. 40, janfev. 2011. 